\title{
Estado-nação, fronteiras, margens Redesenhando os espaços fronteiriços no Brasil contemporâneo
}

\author{
Nation-state, frontiers, margins \\ Redrawing the border areas in contemporary Brazil \\ Marcos César Alvarez \\ Fernando Salla*
}

\begin{abstract}
Resumo: A fronteira é aspecto fundamental do imaginário do estado moderno. Considera-se que as funções centralizadoras e ordenadoras do estado teriam como correlato as fronteiras, os limites da centralização estatal, espaços problemáticos de dominação e de conflito. Discussões contemporâneas nas Ciências Sociais, no entanto, apontam para novas possibilidades de análise, ao enfatizar a heterogeneidade das práticas de poder - que envolvem os dispositivos da soberania, das disciplinas e da gestão governamental. Deve-se pensar menos em fronteiras, como espaços limites e periféricos ao poder central, e mais em margens que se multiplicam e se deslocam tanto na periferia quanto no centro. A investigação em curso busca analisar as novas formas de ação estatal nas fronteiras brasileiras, como o Policiamento Especializado de Fronteira, o Programa Calha Norte e o Sistema Integrado de Saúde das Fronteiras. Palavras-chave: Fronteira. Margem. Estado-nação. Brasil. Violência.
\end{abstract}

Abstract: The border is a fundamental aspect of the imaginary of the modern state. The role of the state as an organizing and centralizing power is related to the idea of borders, the limits of the sovereignty, problematic spaces of domination and conflict. However, contemporary discussions in the Social Sciences field suggest new possibilities for analysis, emphasizing the heterogeneity of practices of the power, involving, simultaneously, devices of sovereignty, disciplines and governmental management. We should think of this space of practices not like borders, space limits and peripheral to the central power, but as margins that are multiplying and moving both in the periphery and in the center. The ongoing research seeks to analyze the new forms of state action on the borders of Brazil, such as the Policiamento Especializado de Fronteira (Specialized Border Policing), the "Calha Norte" Program and the Sistema Integrado de Saúde das Fronteiras (Integrated Border Health System).

Keywords: Frontier. Margin. Nation-state. Brazil. Violence.

\footnotetext{
* Marcos César Alvarez é doutor em Sociologia pela USP, professor do Departamento de Sociologia da FFLCH-USP e pesquisador sênior do Núcleo de Estudos da Violência da USP, em São Paulo, SP, Brasil<mcalvarez@usp.br>. Fernando Salla é doutor em Sociologia pela USP, pesquisador sênior do Núcleo de Estudos da Violência da USP, em São Paulo, SP, Brasil <fersalla@usp.br>.
}

\begin{tabular}{|c|c|c|c|c|c|}
\hline Civitas & Porto Alegre & v. 13 & n. 1 & p. 9-26 & jan.-abr. 2013 \\
\hline
\end{tabular}




\section{Introdução}

As reflexões apresentadas neste artigo são resultantes do projeto de pesquisa Violência e fronteiras, em desenvolvimento no Núcleo de Estudos da Violência da Universidade de São Paulo. ${ }^{1} \mathrm{O}$ objetivo mais amplo da reflexão em curso consiste em identificar e analisar os principais obstáculos à consolidação do estado de direito no Brasil, ao pleno funcionamento da democracia e à garantia dos direitos de cidadania; compreender como são geradas e reproduzidas condições econômicas, sociais, políticas e institucionais que conformam um não-estado de direito e que confrontam o ambiente democrático constituído no país desde os anos 1980. A preocupação específica do projeto Violência e fronteiras consiste em analisar tais questões no âmbito das fronteiras do estado-nação brasileiro. Na atualidade, mudanças decorrentes da assim chamada globalização, como a intensificação dos fluxos populacionais em âmbito internacional e a transformação das atividades econômicas, que reconfiguram os mercados legais e ilegais, têm alterado a própria natureza das fronteiras nacionais e do papel do estado-nação na contemporaneidade.

A presença da violência nas regiões de fronteira é uma das investigações empreendidas pela pesquisa. Por meio do acompanhamento das taxas de homicídio nos municípios de fronteira no Brasil, tem sido possível acompanhar a evolução de aspectos da violência em tais contextos.

Outra linha de investigação se dirige para diversas situações políticas marcadas pela presença da corrupção nas instituições e de atividades criminosas praticadas por agentes públicos, tanto em estados de fronteira como em determinados municípios dessa área. Nesta direção, dois casos são emblemáticos - Acre e Rondônia. O caso do Acre veio a público no final dos anos 1990, quando surgiram naquele estado denúncias de existência de um poderoso grupo instalado nas instituições públicas e que estava envolvido com tráfico de drogas, corrupção, violência policial e execuções sumárias. Essas denúncias provocaram apurações de uma Comissão Parlamentar de Inquérito (CPI), conhecida como CPI do Narcotráfico, em 1999. Entre os acusados de chefiar essas atividades estava o então deputado federal Hildebrando Pascoal, além de outros políticos locais. O segundo caso emblemático foi em Rondônia em 2006 e tornou-se público quando a Polícia Federal desencadeou

O projeto conta com recursos da Fundação de Amparo à Pesquisa do Estado de São Paulo (Fapesp) e do Conselho Nacional de Desenvolvimento Científico e Tecnológico (CNPq), que apoiam respectivamente o Núcleo como Centro de Pesquisa, Inovação e Difusão, Cepid e Instituto Nacional de Ciência e Tecnologia (INCT). Neste artigo, são reapresentadas e reelaboradas algumas discussões já divulgadas em texto anterior (Alvarez; Salla, 2010). 
a Operação Dominó, na qual prendeu 22 pessoas. Foram encarceradas algumas das principais autoridades do poder público local, como o desembargador e presidente do Tribunal de Justiça do Estado, o vice-governador, o presidente da Assembleia Legislativa, um conselheiro do Tribunal de Contas, o exprocurador-geral de Justiça, além de vários assessores dessas autoridades. A acusação sobre eles era de desvio de pelo menos R $\$ 70$ milhões (cerca de U\$ 35 milhões) de verbas públicas, entre junho de 2004 e junho de 2005, através de contratos com base em licitações "viciadas e fraudulentas". Havia ainda suspeitas de existência de um esquema de venda de sentenças judiciais.

Mais recentemente, em setembro de 2010, outro estado que possui parte de seu território na fronteira, o Amapá, esteve às voltas com a Operação Mãos Limpas da Polícia Federal que prendeu 18 pessoas, dentre elas o próprio governador do estado, o ex-governador que havia se desincompatibilizado do cargo para concorrer ao Senado, o presidente do Tribunal de Contas do Estado e o secretário de Segurança Pública. A Polícia Federal apontou indícios de atos ilícitos praticados com o objetivo de desvio de verbas públicas. As principais acusações eram de corrupção ativa e passiva, lavagem de dinheiro, fraude em licitações, formação de quadrilha etc.

Por fim, dois municípios de fronteira também foram colocados em debate, o primeiro por conta da violência e dos constrangimentos ao funcionamento das instituições judiciárias e da segurança pública, e o segundo mais uma vez por conta das denúncias de corrupção no meio político local. O primeiro caso refere-se ao atentado sofrido em abril de 2010 pelo senador paraguaio Robert Acevedo, em Pedro Juan Caballero, cidade paraguaia gêmea da brasileira Ponta Porã (MS). Os agressores dispararam dezenas de tiros sobre o carro em que estava; o seu motorista e um segurança morreram na hora. O senador mesmo alvejado por dois disparos de arma de fogo só teve ferimentos leves. $\mathrm{O}$ atentado foi atribuído a traficantes de drogas e grupos criminosos (inclusive de São Paulo), que já teriam feito ameaças à vida do senador paraguaio, desde o período em que havia sido governador do Departamento de Amambay (cerca de 110 mil habitantes), em meados dos anos 2000, quando em conjunto com um juiz federal brasileiro, Odilon de Oliveira, haviam tido um forte enfrentamento ao tráfico de drogas. O segundo município foi Dourados (MS), quando em setembro de 2010 a Operação Uragano, da Polícia Federal, prendeu 28 pessoas acusadas de envolvimento em fraudes em licitações, corrupção ativa e formação de quadrilha. "Entre os presos estão o prefeito da cidade, Ari Artuzi (PDT), a primeira-dama, quatro secretários e nove vereadores, incluindo o presidente da Câmara, Sidlei Alves 
da Silva (DEM)". ${ }^{2}$ A operação desencadeou um colapso político na cidade, ficando apenas um vereador na Câmara, e havendo fortes manifestações de revolta por parte da população.

As situações e acontecimentos apontados acima colocam importantes indagações acerca do funcionamento da democracia no Brasil, especialmente em relação a um critério fundamental do estado democrático de direito, como é a accountability. Da mesma forma, estes cenários colocam em questão a convivência de regimes democráticos com territórios dominados pela violência, pelo assim chamado crime organizado, pela corrupção sistêmica que atravessa as esferas do legislativo, do executivo e do judiciário. No caso brasileiro, um conjunto possível de indagações poderia colocar em questão se tais cenários de violência e de crise não ocorreriam exclusivamente por se tratarem de regiões distantes dos centros econômicos e políticos do país. Entretanto, a presença da violência, da corrupção e de formas diversas de ilegalismos nas grandes metrópoles e nos estados economicamente mais desenvolvidos da federação indica os limites de tal explicação. Ainda assim, por um lado, seria possível indagar se o contexto da fronteira não seria de algum modo uma dimensão com algum peso na explicação de tais acontecimentos. Por outro lado, a investigação da violência na fronteira, por meio da sistematização das taxas de homicído nos municípios aí englobados, permite aprofundar a questão da especificidade da violência nessas regiões, indagar acerca das formas peculiares de conflito que aí se estabelecem. Por último, mas não menos importante, o que está em jogo também é o próprio imaginário do estado moderno, a forma de analisar seu papel e limites diantes das transformações da contemporaneidade. São essas questões que o projeto busca desenvolver, sendo que alguns resultados já obtidos são apresentados aqui.

\section{Um campo da reflexão}

A questão da fronteira é um aspecto fundamental do imaginário do estado moderno. Geralmente, considera-se que as funções centralizadoras e ordenadoras do estado teriam como seu correlato as fronteiras, os limites da centralização estatal, espaços problemáticos de dominação e de conflito.

No âmbito da História e das Ciências Sociais, o tema das fronteiras aparece tanto como dimensão da própria modernidade ou como seu desafio ou avesso. Assim, por um lado, Frederick Jackson Turner (1961) sustentava que a expansão da fronteira norte-americana na direção oeste representava o espaço

\footnotetext{
2 "PF prende prefeito, presidente da Câmara e mais 26 por fraude em licitações no MS", 01/09/2010, Jornal Folha de S. Paulo, acesso Folha.com.
} 
constante de criação, de reelaboração das dinâmicas sociais e econômicas, de incremento do individualismo e consequentemente de "promoção da democracia" no país. José de Souza Martins (2008), em contrapartida, argumenta que a fronteira não se constitui necessariamente como espaço do novo, da modernização, mas no caso brasileiro seria praticamente seu oposto, espaço da recriação/renovação do arcaico, como o trabalho escravo, o extermínio de indígenas etc. $\mathrm{O}$ avanço da frente de expansão econômica, da racionalidade empresarial, burocrática não suprimiu, no caso brasileiro, as formas sociais e econômicas existentes nas áreas alcançadas, mas foram acomodadas e recompostas nas formas de dominação pessoal, na captura das instituições públicas pelos interesses privados, na adoção da violência como prática de solução de conflitos.

Discussões contemporâneas no âmbito das Ciências Sociais, por sua vez, têm apontado para novas possibilidades de análise do tema. Já as reflexões de Michel Foucault (2004) sobre as práticas de poder, sobretudo a ideia do triângulo envolvendo os dispositivos da soberania, das disciplinas e da gestão governamental, permitem dissecar as múltiplas dimensões que se desenvolvem nas fronteiras nacionais: de delimitação e garantia do poder soberano, de organização e institucionalização dos espaços econômicos e sociais e igualmente de gestão cotidiana das populações. Veena Das e Deborah Poole (2008), por sua vez, enfatizam que o estado é sempre um projeto incompleto, que deve ser constantemente enunciado e imaginado, que invoca os limites do fora, do lugar do selvagem, do vazio e do caos. Deste modo, é preciso pensar menos em fronteiras como espaços limites e periféricos ao poder central e mais como margens que se multiplicam e se deslocam tanto na periferia quanto no centro.

Torna-se possível, a partir destas abordagens, problematizar a imagem do estado como forma administrativa de uma organização política racionalizada, que tende a debilitar-se ou desarticular-se somente ao longo de suas fronteiras territoriais e sociais, repensar os limites entre centro e periferia, entre o público e o privado, entre o legal e o ilegal, analisar tais linhas de tensão que atravessam tanto as democracias liberais, completas ou incompletas, quanto os assim chamados estados fracassados. Se a violência e as práticas estatais ordenadoras são chaves para se pensar o problema das fronteiras/margens, também o são as práticas administrativas, as múltiplas linhas de divisão do legal e do ilegal, do normal e do desviante, do cidadão e do não-cidadão, bem como as resistências, as formas de pluralidade legal, econômica, cultural etc.

$\mathrm{Na}$ atualidade, pode-se indagar igualmente se as mudanças advindas da assim chamada globalização, dos novos fluxos populacionais, da intensificação 
das transações econômicas, legais e ilegais, não estariam transformando a própria natureza das fronteiras nacionais e mesmo do próprio estado-nação. Appadurai (2005), por exemplo, busca restituir a complexidade do fenômeno da também chamada mundialização ao colocar como centro de sua análise a noção de fluxo. O que definiria o contemporâneo seria muito mais a circulação do que as estruturas e organizações estáveis. Ao mesmo tempo, não se trataria, mais uma vez, de evocar apenas as recentes inovações tecnológicas e o impacto das novas formas de circulação do capital, mas de buscar uma descrição mais precisa do que está em jogo. Deste modo, para este autor, é a dimensão cultural que está no centro do processo de mundialização, pois as migrações e os fluxos midiáticos colocaram em cheque o estado-nação como centro da imaginação coletiva, ou seja, como referência estável para as construções identitárias da sociedade.

Portes (1999), por sua vez, aponta que o processo de mundialização, em curso nas últimas décadas - visto majoritariamente como o triunfo do livre mercado e da racionalidade econômica e a crise da consciência proletária e da independência nacional - acabou produzindo um interessante paradoxo. Se a revolução tecnológica permitiu uma intensificação da circulação de mercadorias e da comunicação em geral, inaugurou, em contrapartida, uma nova era de lutas sociais. Espécie de Janus bifronte, a mundialização viu nascer - em oposição ao processo de mundialização do capital e de suas elites - a construção, por parte dos trabalhadores, sobretudo imigrantes, de comunidades que atravessam igualmente as fronteiras nacionais. Mesmo que o autor admita que tal processo permanece discreto, apresentaria ainda assim grandes potencialidades de crescimento, ao desenhar no horizonte uma oposição mais geral à mundialização. Em experiências concretas e como resposta ao processo de mundialização do capital, os indivíduos trabalhadores criaram comunidades que efetivamente atravessam as fronteiras nacionais, ao tecerem relações de natureza múltipla e de forma inédita entre suas sociedades de origem e de acolhimento. Teríamos assim, mesmo que às vezes apenas esboçados, espaços transnacionais, que atravessam as fronteiras geográficas, culturais e políticas, mas espaços diferenciados em relação àqueles produzidos pelo capital.

Tarrius $(2000,2002)$ desenvolve seus argumentos na mesma direção, baseados em detalhadas pesquisas de campo. Ele se volta para a caracterização concreta de novos protagonistas da mundialização, os "nômades" da nova ordem - migrantes argelinos, marroquinos, italianos, turcos, poloneses, ciganos etc. - que circulam por diversas regiões da Europa - por cidades como Marselha, Nápoles, Toulon, Montpellier, Nimes, Perpignan, Tarragona, Lérida, Barcelona, Alicante, Granada, Málaga e por países como Argélia, Marrocos, 
Tunísia, Senegal e todo o entorno do Mediterrâneo - que, em seu movimento, desenham um dispositivo comercial com vocação internacional que está associado à construção de novas formas culturais, de novas experiências de vida, de novas formas de sociabilidade que indicam um aspecto surpreendente da mundialização. Outra visão da mundialização, assim, está em jogo, pois nem é possível separar o econômico do social e do cultural. A própria troca realizada nesses mercados tem como condição de possibilidade a construção de complexas redes sociais e simbólicas, a partir das quais os atores envolvidos se constroem paralelamente como sujeitos de suas existências pessoais, mesmo que, por vezes, acossados por grupos mafiosos ou pelo islamismo radical. Para Tarrius, essa nova sociabilidade nômade, produzida por esses fluxos migratórios, se oporia aos espaços controlados pelo estado-nação, como o espaço Schenguen, ao impor novas fronteiras, ao seguir outras racionalidades (Tarrius, 2002, p. 19). Ou seja, em relação a esses novos espaços transnacionais, o estado-nação, em contrapartida, permaneceria como feroz guardião de cidadanias sedentárias, de territórios que lhe escapam e que ele não sabe gerir, daí o crescimento das práticas de encarceramento, de expulsão e de imobilização.

Muitas dessas análises, embora apontem para aspectos essenciais das transformações sociais contemporâneas - importância dos novos fluxos migratórios e das correlatas construções identitárias, mundialização par le bas, novo comospolitismo - trabalham com uma visão deficitária da dinâmica do estado-nação, que não se apresenta como algo homogêneo e estável, mas sim como resultado de processos históricos heterogêneos e descontínuos. Ao considerar-se que o estado-nação desempenha um papel apenas negativo, que coloca obstáculos à intensificação dos fluxos humanos, própria da mundialização contemporânea, perde-se de vista um aspecto indissociável dessa mesma mundialização: que novas formas de governo dos homens também estão emergindo e que desenham novos dispositivos de poder na contemporaneidade. As fronteiras, por exemplo, não são diluídas na contemporaneidade, mas ganham nova complexidade em termos econômicos, políticos e sociais.

É a partir destas e de outras problematizações que a investigação em curso busca identificar e analisar, no Brasil, as tensões e os conflitos existentes entre a afirmação soberana do estado-nação, o desenvolvimento econômico da região de fronteira, a construção administrativa dos aparelhos estatais locais com toda a nova economia de gestão de ilegalismos diversos - e a afirmação tardia do estado de direito, que acaba sendo mais reivindicação de entidades e grupos do que consolidação efetiva das instituições democráticas. 
A questão da fronteira, ganha assim, novo estatuto analítico. Não se trata de pressupor que as fronteiras são exclusivamente espaços de rarefação do estado e de ausência de controle da violência, mas é possível indagar igualmente acerca das formas de exercício do poder que são próprias destes espaços, os conflitos específicos que aí surgem bem como as formas diferenciadas de ação dos múltiplos atores, inclusive públicos, que atuam nesses contextos.

Diversas possibilidades de pesquisa emergem a partir dessas reflexões. $\mathrm{O}$ estudo da violência a partir das taxas de homicídio nos municípios da fronteira oferece um material de cunho quantitativo que pode ser explorado, como detalhado a seguir.

\section{Homicídios e violência}

No campo das Ciências Sociais, as taxas de homicídio em diversos contextos temporais e espaciais têm sido empregadas como um importante indicador de mudanças mais gerais nas práticas de violência interpessoal em determinadas sociedades, bem como de transformações nas formas de administração dos conflitos, ou ainda indicando processos mais amplos de “civilização” dos costumes (Mucchielli; Spierenburg, 2009).

É neste sentido que dados disponíveis sobre a ocorrência de homicídios nos 588 municípos da faixa de fronteira no Brasil permitem avaliar a situação dos níveis de violência nessa área, quando comparada ao restante do país. Patamares mais elevados das taxas de homicído podem indicar tensões e conflitos que permeiam as diferentes formas de ilegalismos aí presentes, bem como os limites da ação estatal para fazer valer a lei, para reprimir as atividades ilegais e, enfim, para assegurar o direito à vida às populações da região.

Tendo em vista, como já afirmado, que as taxas de homicídio podem ser indicativas da intensidade da violência interpessoal, das formas de administração dos conflitos e mesmo de processos mais amplos de recomposição dos costumes, realizou-se um levantamento, com base nos dados de mortalidade do Ministério da Saúde (Datasus), ${ }^{3}$ para o período 1997 a 2009, buscando identificar o comportamento das taxas de homicídio por 100 mil habitantes nos municípios da faixa de fronteira e compará-las com as dos demais municípios brasileiros. ${ }^{4}$

3 Utilizou-se a opção óbitos por causas externas, por ocorrência - Grande Grupo CID 10, X85-Y09 Agressões. Os dados de 2009 são preliminares.

4 A faixa de fronteira compreende o território de $150 \mathrm{~km}$ a partir do limite entre o Brasil e seu vizinho e está prevista na Constituição Federal, de 1988, no seu art. 20, § 2o , e tem uma regulação específica das atividades permitidas e proibidas nessa área desde 1979 com a lei nº 6.634 de 1979 . 
Nesse período, o Brasil possuía 5565 municípios, dos quais 588 estavam na faixa de fronteira. A população nessa faixa estava em torno de 10 milhões de habitantes. Apenas três capitais se encontravam nessa faixa (Boa Vista, Rio Branco e Porto Velho) e somente dois municípios tinham uma população média, no período de 1997-2009, entre 300 e 400 mil habitantes. Acima de 400 mil habitantes não havia nenhum município localizado na faixa de fronteira. Ou seja, os municípios da faixa de fronteira podem ser considerados de pequeno porte, uma vez que a maioria deles $(81 \%)$ tinha população até 20 mil habitantes.

Ao se comparar as taxas médias de homicídio entre 1997 a 2009, apuradas para dois grupos - os municípios da faixa de fronteira e os do restante do Brasil-, verificou-se que as taxas da faixa de fronteira, no geral, são mais elevadas do que as do restante do país. A tabela 1 mostra a distribuição das ocorrências nos municípios da faixa de fronteira e nos demais municípios brasileiros. Nota-se a incidência de taxas mais elevadas de homicídio nos municípios de fronteira em cinco das oito classes de tamanho de municípios, nas quais há possibilidade de comparação. Na classe de 50 a 100 mil habitantes, por sua vez, a taxa é muito próxima entre os dois grupos. A diferença mais expressiva nas taxas de homicídio entre um e outro grupo está naquela classe de municípios entre 200 e 300 mil habitantes, na qual os de fronteira apresentam proporcionalmente maior violência (taxa média de 45,5 em relação a 33,1 do restante do país).

A presença de taxas mais elevadas na faixa de fronteira para diversas classes de tamanho de município ganha ainda mais destaque ao se considerar que, no Brasil, é expressivo sobretudo o número de homicídios concentrados nos 34 municípios brasileiros com mais de 500 mil habitantes, sendo que é justamente a violência em tais municípios que acaba atraindo a atenção da opinião pública e dos pesquisadores. No entanto, não há municípios com mais de 400 mil habitantes na faixa de fronteira. A população concentrada naqueles 34 municípios (cerca de 50 milhões de habitantes) representa pouco mais de $30 \%$ de toda a população brasileira para o período. Porém, os homicídios nestes 34 municípios foram mais de 21 mil, ou seja, $45,1 \%$ de todos os homicídios do país. Nesse sentido, pode-se constatar que os homicídios têm forte incidência no espaço das grandes cidades, mas estas representam apenas $0,6 \%$ do total de municípios. O que sugere que haja uma dispersão das demais ocorrências de homicídio - 54,9\% - por uma vasta rede de municípios, principalmente de pequeno porte, e nesse sentido é que se tornam ainda mais expressivos os dados sobre os municípios de fronteira em relação aos do restante do país em muitas das classes de tamanho apresentadas na tabela 1 que segue. 


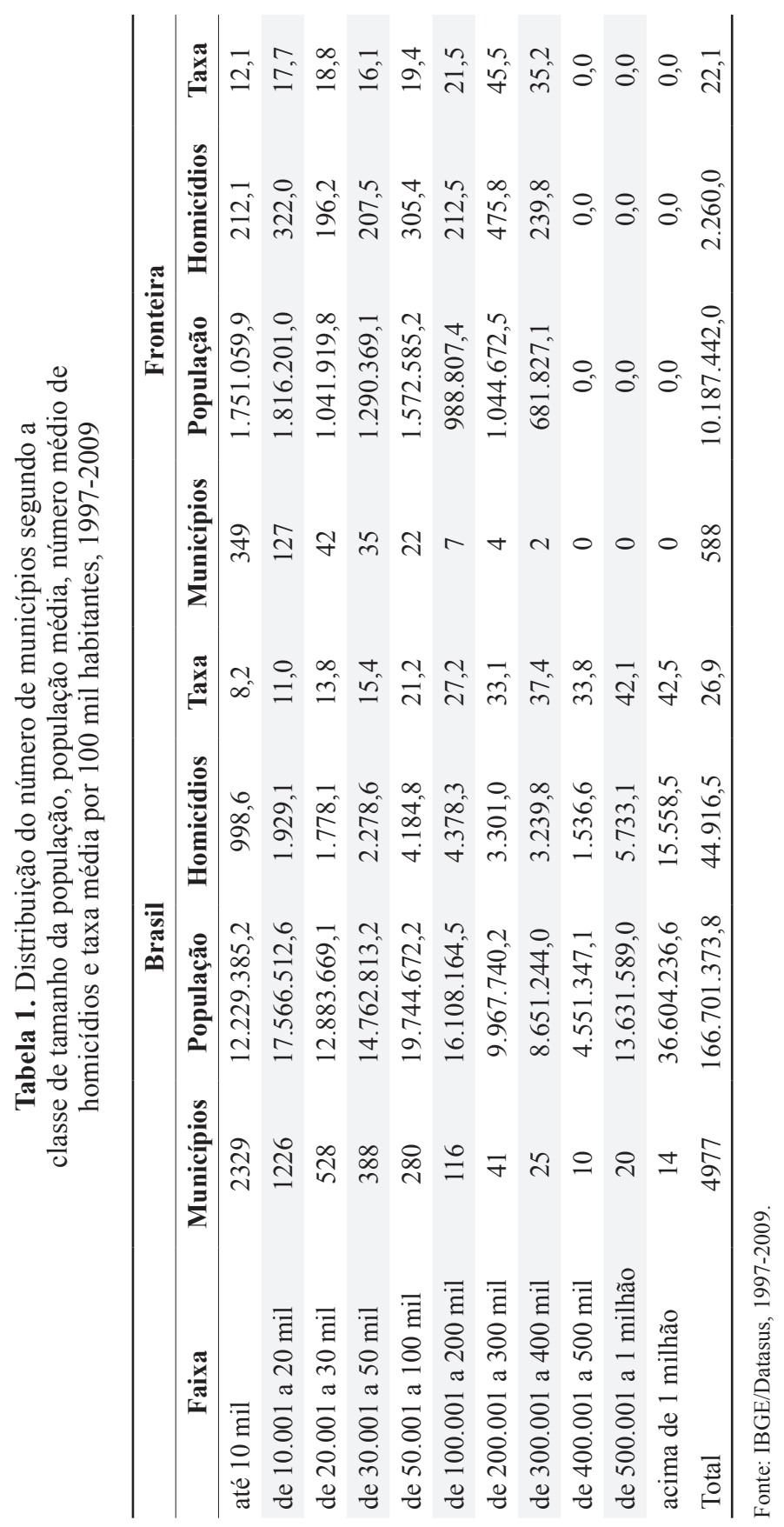


A tabela 2 abaixo também compara os municípios da faixa de fronteira com os do restante do Brasil, segundo as taxas médias de homicídio. Foram criadas categorias de taxas médias e verificadas as ocorrências nos municípios dos dois grupos. No Brasil, ao longo de treze anos, 5,9\% de seus municípios não tiveram qualquer ocorrência de homicídio. No entanto, 4,8\% dos municípios da faixa de fronteira não tiveram nenhuma ocorrência. Um percentual maior de municípios sem homicídios indicaria menos violência, logo o percentual permite supor maior violência na faixa de fronteira.

Tabela 2. Distribuição do número de municípios, segundo a taxa média de homicídios por 100 mil habitantes, 1997-2009

\begin{tabular}{ccccc}
\hline Taxa & Brasil & \% & Fronteira & \% \\
\hline Zero & 293 & 5,9 & 28 & 4,8 \\
2,1 a 1,9 & 270 & 5,4 & 20 & 3,4 \\
4,0 a 3,9 & 706 & 14,2 & 46 & 7,8 \\
6,0 a 7,9 & 659 & 13,2 & 55 & 9,4 \\
8,0 a 9,9 & 594 & 11,9 & 60 & 10,2 \\
\hline Subtotal & 458 & 9,2 & 57 & 9,7 \\
\hline 15,0 a 14,9 & 2980 & 59,9 & 266 & 45,2 \\
20,0 a 24,9 & 789 & 15,9 & 110 & 18,7 \\
25,0 a 29,9 & 436 & 8,8 & 82 & 13,9 \\
\hline Subtotal & 250 & 5,0 & 48 & 8,2 \\
\hline 30,0 a 39,9 & 137 & 2,8 & 29 & 4,9 \\
40,0 a 49,9 & 1612 & 32,4 & 269 & 45,7 \\
50,0 a 59,9 & 192 & 3,9 & 27 & 4,6 \\
60,0 a 69,9 & 96 & 1,9 & 13 & 2,2 \\
70,0 a 79,9 & 56 & 1,1 & 8 & 1,4 \\
80,0 a 89,9 & 19 & 0,4 & 1 & 0,2 \\
90,0 a 99,9 & 15 & 0,3 & 2 & 0,3 \\
mais de 100 & 2 & 0,0 & 1 & 0,2 \\
\hline Subtotal & 4 & 0,1 & 1 & 0,2 \\
\hline Total & 1 & 0,0 & 0 & 0,0 \\
\hline
\end{tabular}

Fonte: Datasus/IBGE, 1997-2009.

De um modo geral, pela tabela constata-se que quando as taxas são mais baixas, até 9,9, os municípios da faixa de fronteira têm uma participação menor que as dos municípios brasileiros em geral. Assim, as taxas mais baixas de homicídio (até 9,9) estão em 59,9\% dos municípios brasileiros, mas na faixa de fronteira representam apenas $45,2 \%$ do total de municípios da faixa. Já quando as taxas de homicídio ficam mais elevadas, indicando, portanto, mais violência, o percentual dos municípios de fronteira é superior em praticamente todas as categorias criadas em relação ao restante dos municípios do país. 
A observação sobre as taxas de homicídio na faixa de fronteira tem permitido, deste modo, levantar perguntas que abrem um campo variado de investigações, como por exemplo, o peso das atividades ilegais e dos fluxos econômicos e de pessoas nos marcos das novas dinâmicas das economias globalizadas e como afetam aquelas taxas. Ou ainda como podem essas taxas estar associadas às disputas locais envolvendo novas atividades econômicas (agronegócio) com antigas atividades de grupos camponeses ou indígenas etc. Porém, mais importante, no âmbito de nossa pesquisa, são as correlações possíveis das ocorrências de homicídio na faixa de fronteira em relação aos limites que apresentam os aparatos de estado - municipais, estaduais ou federais - para fazer valer a lei, para coibir as atividades ilegais, para assegurar aos cidadãos o exercício de seus direitos.

\section{Novas formas de gestão das fronteiras}

Uma última linha de pesquisa que se descortina a partir das reflexões aqui colocadas aponta para a análise das formas de ação estatal que se desdobram atualmente nas fronteiras nacionais. Novas formas de gestão política dos espaços fronteiriços têm sido propostas pelo governo federal (em articulação com os governos dos estados) que combinam os elementos de afirmação da soberania e de defesa do território com preocupações específicas relativas à segurança pública - como o tráfico de drogas e de armas, o abigeato, o contrabando etc. A faixa de fronteira, nas duas últimas décadas, tem se tornado, também para o governo federal, uma área de intervenções que se volta para o incentivo ao desenvolvimento local, ao fortalecimento de organizações da sociedade civil etc., dentro de uma perspectiva de integração tanto nacional como internacional.

Em junho de 2011, por exemplo, o governo federal, por meio do Decreto n. 7.496, instituiu o Plano Estratégico de Fronteiras, pelo qual buscava "o fortalecimento da prevenção, controle, fiscalização e repressão dos delitos transfronteiriços e dos delitos praticados na faixa de fronteira brasileira" (art. $1^{\circ}$ ). A diretriz que norteia o decreto claramente aponta para a necessidade de integração: "I - a atuação integrada dos órgãos de segurança pública e das Forças Armadas; e II - a integração com os países vizinhos" (incisos I e II do art. $2^{\underline{o}}$ ). Evidencia-se, também, que as questões de afirmação e defesa da soberania, tão marcantes em períodos históricos anteriores, passam a ter uma nova composição que é atravessada cada vez mais pela ameaça das ações criminosas transfronteiriças. As Forças Armadas entram decisivamente no enfrentamento das questões dos crimes que marcam as áreas de fronteira no mundo contemporâneo, da mesma forma que as forças de segurança pública, como as polícias estaduais, passam a integrar os esforços desse Plano para uma 
atuação conjunta. Grupos de gestão integrada e centros de operações conjuntas revelam a nova gramática adotada na formulação do Plano.

Sem grandes alterações na sua concepção, esse Plano segue iniciativa tímida que havia sido lançada pelo governo federal, em 2009, o Pefron Policiamento Especializado de Fronteira, que tinha como objetivo criar grupos especiais para atuar na prevenção e na repressão, sobretudo nas regiões de fronteira. Tal iniciativa deveria promover igualmente a cooperação entre União, estados e municípios e entre as diferentes instituições de segurança pública. Por integrar um amplo programa do governo federal voltado para a segurança pública - o Pronasci - Programa Nacional de Segurança Pública com Cidadania - o Pefron era também conhecido como Pronasci Fronteiras. Seus objetivos específicos se voltavam para a melhoria da gestão da área de segurança por meio da integração dos diversos atores envolvidos, como a polícia federal, a polícia rodoviária federal, a polícia civil do estado e a polícia militar; para ações coordenadas com outros órgãos federais.

O Ministério da Defesa, por sua vez, já desenvolvia ações diretamente relacionadas à defesa do território, mas também adotou medidas no sentido de promover um novo tipo de gestão das áreas fronteiriças, como se evidencia não só pela participação no Plano Estratégico de Fronteiras, como pelas alterações no Projeto Calha Norte, que foi criado em 1985, voltado basicamente para os aspectos militares e que em 1997 se transformou em Programa Calha Norte(PCN). O Programa busca aumentar a presença do poder público na região amazônica, contribuir para a defesa nacional, proporcionar assistência as suas populações e fixar as populações nas fronteiras, especialmente as dos estados do Amapá, Acre, Amazonas, Rondônia, Roraima e os municípios da calha norte do rio Amazonas, no estado do Pará e a ilha do Marajó. O Programa atua em duas vertentes: uma civil e outra militar. Nesta última, recursos orçamentários são alocados para o Exército, a Marinha e a Aeronáutica implantarem e ampliarem suas unidades nessa região. Na civil, o Ministério faz convênios com estados e municípios para projetos de infraestrutura básica, complementar e a aquisição de equipamentos, que servirão de pólos irradiadores do desenvolvimento social sustentável. Os recursos são destinados, por exemplo, para construção de bibliotecas, de creches, de hospitais, de rodoviárias nos municípios conveniados.

Os exemplos de tais iniciativas são igualmente respostas às tensões políticas que pautam o debate sobre o "abandono" da faixa de fronteira, a necessidade de defesa das fronteiras, de um controle mais estreito dos crimes transnacionais, de um controle maior sobre os fluxos econômicos ilegais (como contrabando, abigeato) e de população. Nesse sentido, além das demandas por uma presença maior das Forças Armadas no espaço das fronteiras, reafirmando 
seu papel de defesa da soberania do estado, o controle sobre os fluxos - de pessoas e mercadorias - tornou-se um dos mais destacados alvos das tensões no debate político sobre as fronteiras no Brasil.

A presença e atuação de dois órgãos federais - a Receita Federal e a Polícia Federal - no controle desses fluxos, demarca o debate. Estudo preparado pelo Sindicato Nacional da Carreira Auditoria da Receita Federal do Brasil (Sindireceita), em 2010, fez um diagnóstico da presença da Receita Federal na fronteira brasileira (Godoi; Castro, 2010). A partir das informações existentes nesse estudo, foi produzido o quadro 1 que procurou correlacionar as unidades daquele órgão com a sua distribuição pelos municípios da faixa de fronteira.

Quadro 1. Distribuição das unidades da Receita Federal do Brasil pelos municípios da faixa de fronteira, segundo os estados e tipos de cidades, 2010

\begin{tabular}{|c|c|c|c|c|c|l|}
\hline Estado & $\begin{array}{c}\text { Total na } \\
\text { faixa de } \\
\text { fronteira }\end{array}$ & CG & LF & FF & $\begin{array}{c}\text { Unidades } \\
\text { RFB* }\end{array}$ & \multicolumn{1}{|c|}{$\begin{array}{l}\text { Municípios de fronteira com } \\
\text { unidades da RFB }\end{array}$} \\
\hline AC & 22 & 04 & 13 & 05 & 03 & $\begin{array}{l}\text { Assis Brasil - Brasileia - Plácido } \\
\text { de Castro }\end{array}$ \\
\hline AP & 08 & 01 & 01 & 06 & 01 & Oiapoque \\
\hline AM & 21 & 01 & 07 & 13 & 01 & Tabatinga \\
\hline MT & 28 & 00 & 04 & 24 & 01 & Cáceres \\
\hline MS & 44 & 05 & 07 & 32 & 04 & $\begin{array}{l}\text { Corumbá - Mundo Novo - Ponta } \\
\text { Porã - Porto Murtinho }\end{array}$ \\
\hline PA & 05 & 00 & 03 & 02 & 00 & - \\
\hline PR & 139 & 03 & 14 & 122 & 05 & $\begin{array}{l}\text { Capanema - Foz do Iguaçu - } \\
\text { Guaíra - Santa Helena - Santo } \\
\text { Antonio do Sudoeste }\end{array}$ \\
\hline RS & 197 & 10 & 19 & 168 & 12 & $\begin{array}{l}\text { Bagé - Barra do Quará - Chuí - } \\
\text { Itaqui - Jaguarão - Porto Mauá - } \\
\text { Porto Xavier - Quaraí - Santana } \\
\text { do Livramento - São Borja - Três } \\
\text { Passos - Uruguaiana }\end{array}$ \\
\hline RO & 27 & 01 & 08 & 18 & 01 & Guajará-Mirim \\
\hline RR & 15 & 02 & 07 & 06 & 02 & Bonfim - Pacaraima \\
\hline SC & 82 & 01 & 09 & 72 & 02 & $\begin{array}{l}\text { Dionísio Cerqueira - São Miguel } \\
\text { do Oeste }\end{array}$ \\
\hline Total & 588 & 28 & 92 & 468 & 32 & \\
\hline
\end{tabular}

Fonte: * Inspetorias. Levantamento feito em fevereiro de 2011.

Notas: (1) CG - Cidades-gêmeas - pertencem à faixa de fronteira, mas são cidades que possuem uma outra cidade além dos limites nacionais; LF - Linha de fronteira - nessa condição estão os municípios que têm os seus limites coincidentes com os limites do estado nacional. Elas também pertencem à faixa de fronteira; FF - Faixa de fronteira - todos os municípios que não se encontram na linha de fronteira ou que sejam cidades-gêmeas e se encontram nos limites legais de $150 \mathrm{~km}$ a partir do limite do estado brasileiro. (2) Além das inspetorias que estão localizadas principalmente nas cidades-gêmeas, a Secretaria da Receita Federal mantém as Delegacias da Receita Federal. São apenas nove as delegacias que estão localizadas em cidades da faixa de fronteira: AC - Rio Branco; MS - Dourados; PR - Cascavel e Foz do Iguaçu; RS - Pelotas, Santo Ângelo e Uruguaiana; RO - Porto Velho; RR - Boa Vista. Por fim, há a categoria de Alfândega da Receita Federal sendo a única na faixa de fronteira a do município de Rio Grande (RS). 
Uma constatação que se pode fazer, com base no Quadro 1, é que é modesta, na faixa de fronteira, a presença desse órgão essencial de controle sobre a entrada e saída do país de mercadorias e pessoas. São apenas 32 unidades da Receita Federal, sendo que somente as cidades-gêmeas são 28 ao longo de toda a fronteira do Brasil. Nos demais municípios da faixa de fronteira, essa presença é praticamente inexistente.

Com relação à presença de unidades da Polícia Federal nos municípios da faixa de fronteira, a situação não é muito diferente da Receita Federal e tem servido de argumento para as críticas que são feitas, no debate político, sobre as fronteiras brasileiras e seu "abandono". O quadro 2 mostra a distribuição das unidades da Polícia Federal pelos municípios da faixa de fronteira. Notase que são apenas 30 unidades para um total de 588 municípios existentes na faixa de fronteira.

Quadro 2. Distribuição das unidades da Polícia Federal pelos municípios da faixa de fronteira, segundo os estados e tipos de cidades, 2010

\begin{tabular}{|c|c|c|c|c|c|l|}
\hline Estado & $\begin{array}{c}\text { Total na } \\
\text { faixa de } \\
\text { fronteira }\end{array}$ & CG & $\mathbf{L F}$ & $\mathbf{F F}$ & $\begin{array}{c}\text { Unidades } \\
\mathbf{P F} *\end{array}$ & $\begin{array}{l}\text { Municípios de fronteira com } \\
\text { unidades da PF }\end{array}$ \\
\hline AC & 22 & 04 & 13 & 05 & 03 & $\begin{array}{l}\text { Rio Branco - Cruzeiro do Sul - } \\
\text { Epitaciolândia }\end{array}$ \\
\hline AP & 08 & 01 & 01 & 06 & 00 & - \\
\hline AM & 21 & 01 & 07 & 13 & 01 & Tabatinga \\
\hline MT & 28 & 00 & 04 & 24 & 01 & Cáceres \\
\hline MS & 44 & 05 & 07 & 32 & 04 & $\begin{array}{l}\text { Corumbá -Dourados - Naviraí - } \\
\text { Ponta Porã }\end{array}$ \\
\hline PA & 05 & 00 & 03 & 02 & 01 & Óbidos \\
\hline PR & 139 & 03 & 14 & 122 & 03 & $\begin{array}{l}\text { Foz do Iguaçu - Guaíra - } \\
\text { Cascavel }\end{array}$ \\
\hline RS & 197 & 10 & 19 & 168 & 09 & $\begin{array}{l}\text { Bagé - Chuí - Jaguarão - } \\
\text { Pelotas - Rio Grande - Santana } \\
\text { do Livramento - Santo Ângelo } \\
\text { - São Borja - Uruguaiana }\end{array}$ \\
\hline RO & 27 & 01 & 08 & 18 & 03 & $\begin{array}{l}\text { Porto Velho - Guajará-Mirim - } \\
\text { Vilhena }\end{array}$ \\
\hline RR & 15 & 02 & 07 & 06 & 03 & Boa Vista - Bonfim - Pacaraima \\
\hline SC & 82 & 01 & 09 & 72 & 02 & Dionísio Cerqueira - Chapecó \\
\hline Total & 588 & 28 & 92 & 468 & 30 & \\
\hline
\end{tabular}

Fonte: *Superintendência, Delegacia ou Posto Avançado. Levantamento feito em fevereiro de 2011 no site $<$ http://www.dpf.gov.br/institucional/pf-pelo-brasil $>$.

Notas: (1) CG - Cidades-gêmeas; LF - Linha de fronteira; FF - Faixa de fronteira. (2) São apenas três as Superintendências na faixa de fronteira, cujas sedes estão nas capitais Rio Branco (AC), Boa Vista (RR) e Porto Velho (RO). Exceto as cidades de Óbidos (PA) e Bonfim (RR), que são apenas Postos Avançados, todas as demais unidades são Delegacias da Polícia Federal. 
Outros ministérios, no âmbito do governo federal, têm atuado no sentido de uma maior "governamentalização" da faixa de fronteira, indo além, portanto, tais iniciativas das preocupações diretas com a defesa e a segurança do território ou mesmo com a manutenção direta da ordem pública e enfrentamento ao crime. O Ministério da Integração Nacional, por exemplo, implantou, em 2009, o Programa de Promoção do Desenvolvimento da Faixa de Fronteira, a primeira iniciativa de alocação de recursos para o desenvolvimento desse território. Os quatro eixos do programa indicam as novas formas de gestão da faixa de fronteira: a) fortalecimento institucional, pelo qual se busca melhorar a capacidade dos municípios e as suas articulações regionais, assim como os vínculos com os órgãos federais interministeriais e ainda estimular a criação de fóruns, comitês relacionados às questões de fronteira, inclusive com os países vizinhos; b) desenvolvimento econômico integrado, com aproveitamento dos potenciais de economia local, capacitação de pessoal, incentivo ao empreendedorismo, crédito às pequenas e médias empresas etc.; c) cidadania, eixo voltado para o fortalecimento de organizações de defesa dos direitos humanos, fortalecimento de grupos minoritários, apoio e divulgação da cultura local etc.; e d) marco regulatório, pelo qual se procura lidar com legislação que rege esta região para que se adapte as suas peculiaridades da zona de fronteira, o que compreende espaços de outros países.

Constitui-se ainda como um exemplo de novo padrão de gestão das áreas de fronteira do Brasil a adoção do Sistema Integrado de Saúde das Fronteiras - SIS Fronteiras, lançado pelo Ministério da Saúde, em 2005. De um lado, o Ministério expressa claramente a questão da integração com o Mercosul como uma das razões da adoção dessa iniciativa. De outro lado, o SIS Fronteiras destina-se a fazer chegar o Sistema Unificado de Saúde (SUS) a essa área. O sistema promoveu a elaboração de um diagnóstico local dos aspectos socioeconômicos, geográficos, epidemiológicos, sanitários, ambientais e assistenciais. Numa outra fase, promoveu a elaboração de um plano operacional destinado ao levantamento, por parte da gestão local em parceria com a universidade federal do respectivo estado, de metas e ações para a melhoria dos serviços de saúde nos municípios de fronteira.

Do SIS Fronteiras desdobrou-se ainda uma iniciativa de formação de quadros de profissionais de saúde e consequente produção de conhecimento que foi a criação de um mestrado profissional sobre Vigilância em Saúde nas Fronteiras. O curso foi criado pela Fiocruz (Fundação Oswaldo Cruz, ligada ao Ministério da Saúde) através da Escola Nacional de Saúde Pública. Também essa proposta busca a integração dos serviços de saúde nos níveis nacional e internacional, especialmente em relação aos países do Mercosul. Dessa forma, 
o mestrado é voltado "aos profissionais de nível superior que atuam na área de vigilância em saúde vinculados ao nível central da Secretaria de Estado de Saúde do Mato Grosso do Sul ou vinculados aos núcleos regionais de saúde, aos técnicos de nível superior da área de vigilância em saúde vinculados às Secretarias Municipais de Saúde, à Agência Nacional de Vigilância Sanitária (Anvisa), à Universidade Federal da Grande Dourados e aos técnicos de nível superior indicados pelo Ministério de Saúde Pública e Bem-Estar Social do Paraguai". 5

Em janeiro de 2010 foi criada a Universidade Federal de Integração Latino-Americana, Unila, sediada, inicialmente em Foz do Iguaçu. Em 2 de setembro de 2010, o presidente Lula, num evento na Unila, em Foz do Iguaçu, criou a Comissão Permanente para o Desenvolvimento e a Integração da Faixa de Fronteira (CDIF), uma espécie de um embrião para um futuro PAC [Programa de Aceleração do Crescimento] das Fronteiras. A Comissão Permanente para o Desenvolvimento e a Integração da Faixa de Fronteira foi instalada efetivamente em abril de 2011, no âmbito do Ministério da Integração Nacional. A gramática da integração entre os órgãos federais, estaduais e municipais também se repete nessa iniciativa.

A análise mais aprofundada de tais ações, em conjunto com o aprofundamento das análises quantitativas das taxas de homicídio nos municípios de fronteira e de futuros estudos de caso voltados para as novas formas locais de gestão dos ilegalismos abrem perspectivas, deste modo, para uma melhor compreensão da natureza do estado-nação na atualidade, das formas de governo dos homens que se voltam para populações cada vez mais móveis e em contextos econômicos cada vez mais transnacionais, e que estão reconfigurando os espaços fronteiriços na contemporaneidade.

\section{Referências}

ALVAREZ, Marcos César; SALLA, Fernando. Violência e fronteiras no Brasil: tensões e conflitos nas margens do estado-nação, paper apresentado no $34^{\circ}$ Encontro Anual da Anpocs, 25 a 29 de outubro de 2010, Caxambú, Minas Gerais, no Seminário Temático ST-37 Violência, Criminalidade e Justiça Criminal no Brasil, 2010. Disponível em: $<$ http://www.anpocs.org.br/portal/index.php?option=com_wrapper\&Itemid=90>.

APPADURAI, A. Après le colonialisme. Les conséquences culturelles de la globalisation. Paris: Payot, 2005.

BOJUNGA, Claudio. Fronteiras: viagem ao Brasil desconhecido. São Paulo: AlfaÔmega, 1978.

\footnotetext{
5 Ver informações em: <http://www.ensp.fiocruz.br/portal-ensp/informe/materia/index.php? origem $=3 \&$ matid $=23275>$.
} 
BRASIL. Ministério da Integração Nacional. Secretaria de Programas Regionais. Programa de Desenvolvimento da Faixa de Fronteira. Proposta de Reestruturação do Programa de Desenvolvimento da Faixa de Fronteira. Brasília: Ministério da Integração Nacional, 2005.

BRASIL. Ministério da Justiça. Secretaria Nacional de Segurança Pública. Gabinetes de Gestão Integrada em Segurança Pública - coletânea 2003-2009. Brasília: Secretaria Nacional de Segurança Pública, 2009.

CPI - COMISSÃO Parlamentar de Inquérito da Camâra Federal. Relatório da Comissão Parlamentar de Inquérito destinada a investigar o avanço e a impunidade do narcotráfico. Brasília: Câmara dos Deputados, 2000.

DAS, Veena; POOLE, Deborah. El estado y sus márgenes: etnografias comparadas. Cuadernos de Antropologia Social, Buenos Aires, v. 27, p. 19-52, 2008.

FOUCAULT, M. Sécurité, territoire, population: cours au Collège de France, 19771978). Paris: Seuil/Gallimard, 2004.

GODOI, Rafael; CASTRO, Sérgio de. Fronteiras abertas: um retrato do abandono da aduana brasileira. Brasília: Sindireceita, 2010.

MARTINS, José de Souza. Fronteira: a degradação do outro nos confins do humano. São Paulo: Contexto, 2008.

MISSE, M. Crime e violência no Brasil contemporâneo: estudos de sociologia do crime e da violência urbana. Rio de Janeiro: Lúmen Juris, 2006.

MUCCHIELLI, Laurent; SPIERENBURG, Pieter (Direction). Histoire de l'homicide en Europe: de la fin du Moyen Âge à nos jours. Paris: La Découverte, 2009.

PORTES, Alejandro. La mondialisation par le bas. Actes de la Recherche en Sciences Sociales, Paris, v. 129, n. 1, p. 15-25, 1999.

TARRIUS, Alain. Les nouveaux cosmopolitisme: mobilités, identités, territoires. La Tour d'Aigues, France: Éditions de l'Aube, 2000.

TARRIUS, Alain. La mondialisation par le bas: les nouveaux nomades de l'économie souterraine. Paris: Balland, 2002.

TURNER, Frederick Jackson. The significance of the frontier in American History. In: LEUCHTENBURG, William; WISHY, Bernard (Ed.). Frontier and section - selected essays of Frederick Jackson Turner. Englewood Cliffs: Spectrum Book, 1961 [1893].

Data de recebimento: 28/11/2011.

Data de aprovação: 30/03/2013.

Autor correspondente:

Marcos César Alvarez

Rua Girassol, 964, ap. 73 - Vila Madalena

05433-002 São Paulo, SP 